\title{
Near death 18 weeks preeclampsia in molar pregnancy
}

\author{
O. Es Saad ${ }^{1}$, Saloua Tanouti2 ${ }^{2 *}$, H. Bkiyar ${ }^{1}$, A. Mimouni ${ }^{2}$, B. Housni ${ }^{1}$
}

\begin{abstract}
${ }^{1}$ Department of Anesthesia Resuscitation, Mohammed VI University Hospital Center, Oujda, Morroco
${ }^{2}$ Department of Gynecology and Obstetrics, Mohammed VI University Hospital Center, Oujda, Morroco
\end{abstract}

Received: 26 November 2019

Revised: 24 December 2019

Accepted: 31 December 2019

\author{
*Correspondence: \\ Dr. Saloua Tanouti, \\ E-mail: saloua.tanouti@gmail.com
}

Copyright: (C) the author(s), publisher and licensee Medip Academy. This is an open-access article distributed under the terms of the Creative Commons Attribution Non-Commercial License, which permits unrestricted non-commercial use, distribution, and reproduction in any medium, provided the original work is properly cited.

\begin{abstract}
Authors present a case of a molar pregnancy of 18 weeks with preeclampsia complicated with acute pulmonary oedema. A condition carrying a significant risk to mother, therefore, raising an important issue on preeclampsia symptoms on pregnancies before 20 weeks. A 31-year-old woman gravida 2, parity 1 presented with dyspnea at 18 weeks' gestation. Blood pressure was very high $(180 / 110 \mathrm{mmHg})$ and there was markedly proteinuria $(+4)$. She had severe dyspnea and her oxygen saturation level was $75 \%$. Her chest X-ray graph showed massive acute pulmonary oedema. Ultrasonography shows endometrial cavity containing multiple small cystic spaces, creating a characteristic "snowstorm" and "cluster of grapes" appearance. Markedly elevated quantitative human chorionic gonadotropin $(250.000 \mathrm{mIU} / \mathrm{mL})$. The acute pulmonary oedema has been managed by diuretics (Furosemide) and oxygen. There was no cardiac abnormalities in the tranthoracic echocardiogram. Authors administered antihypertensive therapy (intravenous nicardipine and lmethyldopa in per os), and magnesium sulfate in prevention of eclamptic seizures. The pregnancy was terminated by uterine evacuation under oxytocin infusion by manual ultrasound aspiration. She was followed up intensive care unit for two days. Causes of secondary high blood pressure had been eliminated. The patient's blood pressure rapidly normalized two days after delivery. Dyspnea disappeared one day later. Pathologic and cytogenetic analyses revealed a complete hydatiform mole. Two days after delivery; the serum $\beta$-hCG level was $99000 \mathrm{mlU} / \mathrm{ml}$. A control ultrasonography shows an empty uterus. Hydatidiform mole is classified into 2 different subtypes, complete hydatidiform mole and partial or incomplete hydatidiform mole development of preeclampsia prior to 20 weeks of gestation should prompt a clinical evaluation to exclude the possibility of an underlying hydatidiform molar pregnancy. Ultrasonography and level of serum BHCG are the initial investigation of choice for the detection of hydatidiform mole. Aspiration is the treatment of reference.
\end{abstract}

Keywords: Acute pulmonary oedema, High blood pressure, Molar pregnancy, Ultrasound

\section{INTRODUCTION}

Hydatiform mole (HM) is a trophoblastic disease characterized by polycystic and hydropic degeneration of some or all of the chorionic villi. It is a benign entity but whose identification matters for two reasons: it can evolve towards clinically malignant entities, and the classifications of trophoblastic neoplasia that determine the therapeutic management take into account the type of initial gestation. ${ }^{1}$

$\mathrm{HM}$ can be categorized as complete mole (CHM) and partial mole (PHM) dissimilar by epidemiology, clinical presentation, anatomopathology and genetics. The diagnosis of $\mathrm{HM}$ is done by ultrasound and the quantitative determination of $\beta$-hCG. Clinically HM is 
revealed by recurrent genital bleeding and exaggeration of the sympathetic signs of pregnancy (nausea and vomiting) with increase of the uterine volume compared to the gestational age, is usually conventional when it comes to a CHM.

Early preeclampsia in case of CHM is a rare event, recorded in about $5 \%$ of cases and less clear mechanism. ${ }^{2}$

Authors report the case of a CHM alarmed by CHBP with severe preeclampsia complicated by acute pulmonary oedema on added to a 31-year-old pregnant, whose evolution of blood pressure was decreasing after aspirational curettage of the product design. Authors will remind clinic of an illness and pathogeny of various signs.

\section{CASE REPORT}

A pregnant woman 31 years old, P2G1A0, with no history of diabetes, nor high blood pressure (HBP), was transferred from a peripheral health center for acute pulmonary oedema with high blood pressure on pregnancy of 18 weeks (WA). About 2 weeks before, she complained of heavy vomiting treated with antispasmodics and antiemetics without improvement. A few days later, this clinical picture was enriched by dyspnea and the blood pressure was $180 / 110 \mathrm{mmHg}$, reason for its transfer to the University hospital Mohammed Vi Oujda Morocco.

At admission she had sever dyspnea with a low level of oxygen saturation of $75 \%$, the palpebral conjunctiva were pale; the BP of $180 / 115 \mathrm{mmHg}$. The uterine fundus was palpated $3 \mathrm{~cm}$ below the umbilicus; the cervix admitted the finger pulp, with no endo-uterine bleeding; there was bilateral soft peri-malleolar edema. Ultrasound was used to objectify characteristic honeycomb or snowflake images filling the entire uterine cavity.

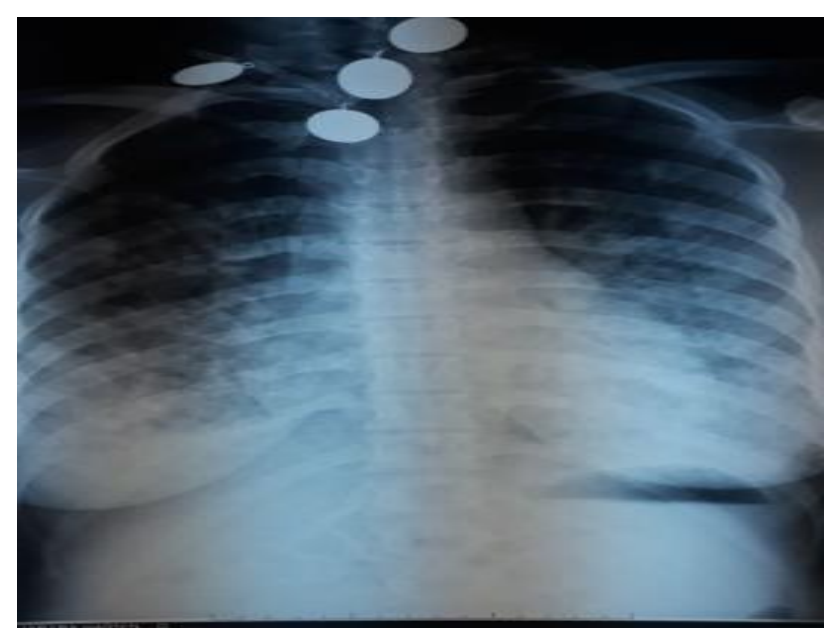

Figure 1: Acute pulmonary oedema.

The chest X-Ray showed signs of acute pulmonary oedema (Figure 1).
The biological assessment showed a hypochromic microcytic anemia and a serum beta-hCG level quantified at $250,000 \mathrm{mIU} / \mathrm{ml}$. The pregnant woman was of the $\mathrm{ORh}+$ blood group; platelets $\left(250,000 / \mathrm{mm}^{3}\right)$, alanine aminotransferase (ALAT $=29$ IU/L), aspartate aminotransferase $($ ASAT $=22 \mathrm{IU} / \mathrm{L})$, urea $(0.3 \mathrm{~g} / \mathrm{l})$ and creatinine $(8 \mathrm{mg} / \mathrm{L})$ were in the norms; albuminuria by dipstick was positive (4+). Albuminuria of 24 hours $4 \mathrm{~g} / 24 \mathrm{H}$ Authors have been diagnosed with severe preeclampsia complicated with acute pulmonary oedema.

There were no cardiac abnormalities in the tranthoracic echocardiogram.

After urgent evaluation of the pregnant woman, authors administered antihypertensive therapy (intravenous nicardipine and methyldopa in per os), and magnesium sulfate in prevention of eclamptic seizures.

The respiratory distress has been managed with oxygenotherapy and intra-venous furasemide.

After information on the complications of a HM and the recommendations of her care, the pregnant woman consented to the termination of the pregnancy that authors had indicated. Thus, authors proceeded to the uterine evacuation under oxytocin infusion by manual ultrasound aspiration. The uterine contents were made of a vesicular mass corresponding to a CHM confirmed by anatomopathological examination.

The principal causes of secondary hypertension were eliminated, biologically There was no hyperthyroidism, and no high level of urinary metanephrin.

The thoracic abdominal pelvic scan showed no surrenal mass and no stenosis of the renal artery. The pelvic scan showed bilateral ovarian cyst.

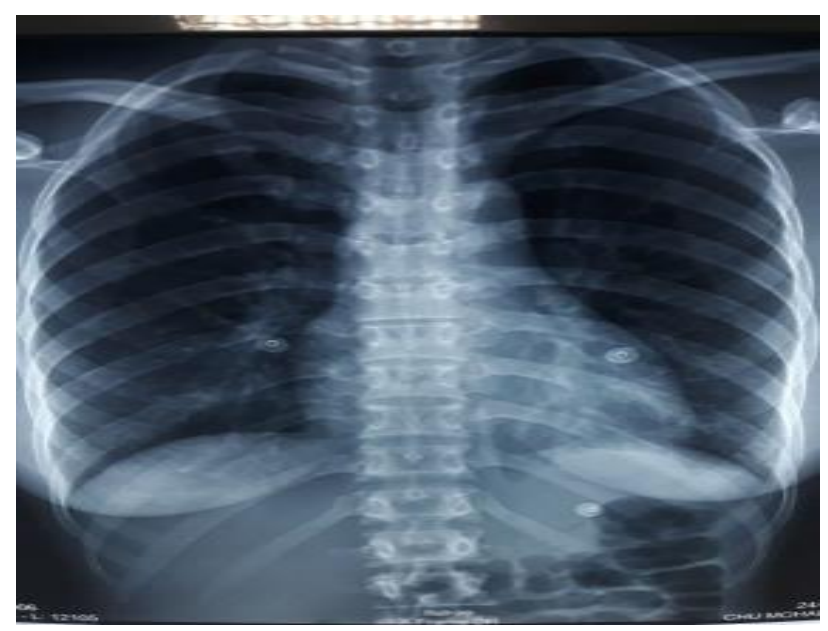

Figure 2: Normal chest X-ray.

In evolution, normalization of blood pressure was dramatic after uterine aspiration. The dyspnea has disappeared with clean control chest X-ray (Figure 2). 
Serum beta-hCG level quantified at 99,000 mIU/ml after 2 days, with an empty uterine cavity at the ultrasound.

The patient is going to be on contraception for 3 months with the 12-month surveillance with serum beta-hCG monitoring.

\section{DISCUSSION}

$\mathrm{HM}$ is a relatively rare complication with an incidence that varies by region of the world and appears to be related to ethnic group, more prevalent in Southeast Asia ( 1 in 2 out of 1000 pregnancies in Japan and China) than in North America and Europe (0.57 to 1.1 out of 1000 pregnancies)..$^{3,4}$

Authors reported in this case the first documented case, in our hospital, of preeclampsia complicated by acute pulmonary oedema on added on a complete hydatiform mole.

The diagnostic was based on ultrasound and high level of serum $\beta$-hCG.

Indeed, HM and preeclampsia are two diseases of pregnancy each characterized by placental dysfunction which is an integral part of the pathological process.

HM may be partial (PHM) or complete (CHM). In the $\mathrm{CHM}$, associated with the presence or expression of the only paternal nuclear genome, hydropic degeneration is complete, and no trace of embryo, amniotic cavity and even vascularization is observed. ${ }^{1}$

CHM is the most common form and represents $80 \%$ of gestational trophoblastic diseases. Its risk factors are numerous. In fact, molar pregnancy is common at extreme ages of reproductive life..$^{5}$ This wasn't the case for our patient aged 31 years.

Low socioeconomic status, nulliparity, race, malnutrition (protein, folate and carotene deficiency), consanguinity, environmental and genetic factors are other risk factors mentioned in the literature. ${ }^{6}$

\section{Our patient presented most of this risk factors}

Low socioeconomic status, nulliparity, malnutrition consanguinity. However, MHC is 10 times more common among women with blood group A whose partner is group $\mathrm{O}$; which is not the case in our case because the patient and her husband are blood group $\mathrm{O}$.

The diagnosis of CHM is classically suggested in a syndrome of first trimester metrorrhagia, exaggeration of sympathetic signs of pregnancy, increased uterine volume compared to gestational age and significant elevation of serum $\beta$-hCG. However, the diagnosis is now easy thanks to the ultrasound, especially when it comes to the CHM. In our case the diagnostic of preeclampsia has been revealed by an acute respiratory distress with no gynecological symptoms.

The exaggeration of sympathetic signs is a frequent occurrence of HM. It is due to hypersecretion of $\beta$-hCG. Indeed, hCG stimulates the corpus luteum to the production of estradiol and progesterone via their receptors luteinizing hormone-chorionic gonadotrophin receptor (LH-CGR) and plays a promotive role in the aromatization of steroids of the placenta. Estrogens, like progesterone, are known inducers of nausea and vomiting. ${ }^{7}$ Its was the case for our patient who has been vomiting two weeks before her admission.

The metrorrhagias, found in $84 \%$ to $97 \%$ of the cases, are spontaneous, capricious, of increasing abundance; and are due to erosion of the uterine walls in the absence of placentation. ${ }^{8}$ In our case there was no metrorrhagias.

The patient can also complain of pelvic pain, present in $20 \%$ of cases and related to the presence of luteal cysts or the expulsion of vesicles. ${ }^{2}$ Our patient didn't suffer from any pelvic pain.

Preeclampsia on added on CHBP (early preeclampsia), defined according to the ISSHG by the occurrence of hypertension before 20 weeks of amenorrhea associated with proteinuria and edema, is a relatively common situation in type I triploidy with partial mole, as described in the paper Rijhsinghani et al. ${ }^{9,10}$ a prevalence of $35 \%$ of cases. Its occurrence at an CHM is a less common situation. Alessandro et al, had recorded it in $5 \%$ of cases. $^{2}$

In Nigeria, Igwebe $\mathrm{AO}$ and Eleje GU had recorded preeclampsia in $9.7 \%$ of all hydati form moles. ${ }^{11} \mathrm{CHM}$, characterized by abnormal proliferation of syncytiotrophoblast and the hydropic degeneration of all chorionic villi, is often accompanied by hemoconcentration and alteration of vascular hemodynamics. Its association with early preeclampsia would suggest that this placentation abnormality is thought to be responsible for excessive production of endogenous antiangiogenic proteins, particularly the soluble form of Fms-like tyrosine kinase 1 (sFlt1). ${ }^{12}$

It is currently shown that preeclampsia clinical manifestations, namely HBP, proteinuria and characteristic renal injury (glomerular endotheliosis) are caused by an excess of anti-angiogenic proteins, particularly the soluble form of Fms-like tyrosine kinase 1 (sFlt1) in the maternal circulation after being overproduced in the placenta. This soluble factor sFlt1 antagonizes or decreases the free maternal circulating levels of angiogenic proteins such as vascular endothelial growth factor (VEGF) and free placental growth factor (PlGF). ${ }^{12,13}$

The free circulating angiogenic factors VEGF and PIGF being essential for endothelial growth, differentiation and 
vascular integrity; and the decrease in vascular resistance and blood pressure. ${ }^{12}$ The antagonistic effect or the decrease in their circulation rate by sFlt1 will explain the occurrence of early preeclampsia during a molar pregnancy. Aghajanian $\mathrm{P}$, think that preeclampsia in the first trimester or early second trimester is an exceptional finding in a normal but pathognomonic pregnancy of one hydatiform mole. ${ }^{14}$

The studies demonstrated that in women conceiving following a pregnancy affected by complete or partial mole, there is an increased risk of repeat hydatidiform mole. The majority, however, will have a non-molar pregnancy, in which the outcome is not significantly different from that of an unselected population. This suggests that a molar pregnancy does not have any direct adverse or residual effects for subsequent obstetric health. ${ }^{15-17}$

\section{CONCLUSION}

Hydatidiform mole is classified into 2 different subtypes, complete hydatidiform mole and partial or incomplete hydatidiform mole based on the epidemiology, cytogenetics, pathology, natural history, and clinical presentation. Development of preeclampsia/eclampsia prior to 20 weeks of gestation should prompt a clinical evaluation to exclude the possibility of an underlying hydatidiform molar pregnancy. Ultrasonography is the initial investigation of choice for the detection of hydatidiform mole. Clinical and laboratory abnormalities may favour a diagnosis of hydatidiform mole and ultrasonography should be performed in all suspected cases to exclude a normal pregnancy and confirm this diagnosis.

Funding: No funding sources Conflict of interest: None declared

Ethical approval: Not required

\section{REFERENCES}

1. Boufettal H, Coullin P, Mahdaoui S, Noun M, Hermas $\mathrm{S}$, Samouh N. Les moles hydatiformes partielles au Maroc: Etude épidémiologique et clinique. EMHJ. 2012;18:755-61.

2. Cavaliere A, Ermito S, Dinatale A, Pedata R. Management of molar pregnancy. J Prenatal Med. 2009;3:15-7.

3. Lurain JR, John I. Gestational trophoblastic disease: epidemiology, pathology, clinical presentation and diagnosis of gestational trophoblastic disease, and management of hydatidiform mole. Am J Obstet Gynecol. 2010;203:531-9.

4. Lee C, Smith HO, Kim SJ. Epidemiology. In: Hancock, B.W., Seckl M.J., Berkowitz R.S. and Cole, L.A., Eds.,
Gestational Trophoblastic Disease, $3^{\text {rd }}$ Edition, ISSTD, McLean; 2009:49-97.

5. Fouogue TJ, Fouélifack YF, Sando Z, Mboudou ET, Doh AS. Grossesse Molaire et Difficultés de Prise en Charge en Milieu Rural: Illustration d'un Cas Clinique à l'Hopital de District de Bogo (Extrême-Nord Cameroun). Clinics in Mother and Child Health, 2011:8.

6. Zulvayanti, Krisnadi SR, Achadiyani. Correlation between three pregnancy characteristics (age, parity, $\beta$ hCG Level) and immunoexpression on complete hydatidiform mole. Open Access Library J. 2017;4:e3634.

7. Anisodowleh N, Farahnaz K, Nasrin J, Maryam H, Elaheh B. Thyroid hormone levels and its relationship with human chorionic gonadotropin in patients with hydatidiform mole. Open J Obstet Gynecol. 2016;6:5663.

8. Chu MM, Ma Y, Tse KY, Chan KK. Cyclophosphamide, hydroxyurea, actinomycin d, methotrexate, and vincristine in the treatment of gestational trophoblastic neoplasia. Int $\mathbf{J}$ Gynecol Cancer. 2015;25:498-503.

9. Beillat T, Dreyfus M. Hypertension artérielle et grossesse. Traité d'obstétrique, Elsevier Masson. 2010:216-225.

10. Rijhsinghani A, Yankowitz J, Strauss RA, Kuller RA, Patil S, Williamson RA. Risk of preeclampsia in second-trimester triploid pregnancies. Obstet Gynecol. 1997;90:884-8.

11. Igwegbe AO, Eleje GU. Hydatidiform mole: a review of management outcomes in a tertiary hospital in SouthEast Nigeria. Ann Med Health Sci Res. 2013;3:210-4.

12. Kanter D, Marshall DL, Wang ER, Borromeo E, Ananthkarumanchi S, Stillman IE. Angiogenic Dysfunction in Molar Pregnancy. Am J Obstetr Gynecol. 2010;202:184e1-184.e5.

13. Lam C, Lim KH, Karumanchi SA. Circulating angiogenic factors in the pathogenesis and prediction of preeclampsia. Hyper. 2005;46:1077-85.

14. Igwegbe AO, Eleje GU. Hydatidiform mole: a review of management outcomes in a tertiary hospital in southeast Nigeria. Annals Med Health Sci Res. 2013;3(2):210.

15. Kim S. Epidemiology. In: Hancock BW, Newlands ES, Berkowitz RS editors. Gestational Trophoblastic Disease. London: Chapman and Hall; 1997:27-42.

16. Berkowitz RS, Tuncer ZS, Bernstein MR, Goldstein DP. Management of gestational trophoblastic disease: subsequent pregnancy experience. Semin Oncol. 2000;27:678-85.

17. Matsui H, Iitsuka Y, Suzuka K, Seki S, Sekiya S. Subsequent pregnancy outcome in patients with spontaneous resolution of HCG after evacuation of hydatidiform mole: comparison between complete and partial mole. Hum Reprod. 2001;16:1274-12.

Cite this article as: Es Saad O, Tanouti S, Bkiyar H, Mimouni A, Housni B. Near death 18 weeks preeclampsia in molar pregnancy. Int J Reprod Contracept Obstet Gynecol 2020;9:877-80. 